\title{
O PROFISSIONAL DE EDUCAÇÃO FÍSICA E A PROMOÇÃO DA SAÚDE EM NÚCLEOS DE APOIO À SAÚDE DA FAMÍLIA
}

\author{
THE PHYSICAL EDUCATION PROFESSIONAL AND THE PROMOTION OF HEALTH AT FAMILY HEALTH \\ SUPPORT CENTERS
}

\section{EL PROFESIONAL DE EDUCACIÓN FÍSICA Y LA PROMOCIÓN DE SALUD EN NÚCLEOS DE APOYO A LA SALUD DE LA FAMILIA}

\author{
Gisele Marcolino Saporetti ${ }^{1}$ \\ Paulo Sérgio Carneiro Miranda ${ }^{2}$ \\ Soraya Almeida Belisário ${ }^{3}$
}

Resumo Os núcleos de apoio à saúde da família configuram-se hoje como um lócus de inserção do profissional de educação física na atenção primária à saúde. Esse fato trouxe novos desafios à atuação desse profissional, como a realização de ações de promoção da saúde nos âmbitos individual e coletivo. O objetivo deste artigo foi analisar as ações realizadas por tal profissional nesses núcleos no estado de Minas Gerais, em 2015. Tratou-se de pesquisa qualitativa e exploratória, que utilizou a pesquisa documental e grupos focais com 15 participantes como instrumentos de coleta de dados. Os resultados demonstraram diferentes e complementares concepções acerca do conceito de promoção da saúde e a realização de ações de promoção abrangentes, diversificadas e em conjunto com a equipe e a comunidade. Fatores como a reorientação do modelo de saúde, a participação da comunidade, a valorização do trabalho multiprofissional e intersetorial e o incentivo governamental para as práticas de atividades físicas foram apontados como facilitadores para a realização dessas ações. Entre as dificuldades, destacaram-se a falta de infraestrutura e de capacitação e a concepção dos demais profissionais, ainda voltada para as ações clínicas individuais, em detrimento de ações coletivas de promoção da saúde.

Palavras-chave pessoal de saúde; educação física; atenção primária à saúde; promoção da saúde.

\begin{abstract}
Today, the family health support centers are a locus for the insertion of the physical education professional in primary health care. This fact has introduced new challenges to the work of this professional, such as the undertaking of health promotion activities at the individual and collective levels. This study aimed to analyze the actions taken by such a professional at these centers in the state of Minas Gerais, Brazil, in 2015 with 15 participants. This was a qualitative, exploratory study, which used the documentary research and focus groups as data collection instruments. The results showed different and complementary conceptions about the health promotion concept and the undertaking of comprehensive and diversified promotion actions together with the team and the community. Factors such as the reorientation of the model of health, community participation, the appreciation of multidisciplinary and intersectoral work, and government incentives for physical activity practices were identified as facilitators to carry out these actions. The greatest perceived difficulties included the lack of infrastructure and training and the conception of other professionals, still focused on individual clinical actions to the detriment of collective actions to promote health.
\end{abstract}

Keywords health workers; physical education; primary health care; promotion of health. 


\section{Introdução}

A criação dos núcleos de apoio à saúde da família (NASFs), por meio da portaria GM/MS n. 154, de 24 de janeiro de 2008, objetivou "ampliar a abrangência e o escopo das ações da atenção básica, bem como sua resolubilidade, apoiando a inserção da Estratégia Saúde da Família na rede de serviços e o processo de territorialização e regionalização a partir da atenção básica" (Brasil, 2008, p. 2). Os NASFs são estruturas de apoio às equipes de saúde da família (SF), compostas por diferentes profissionais, entre eles o profissional de educação física (PEF), que devem, entre outras questões, buscar instituir a plena integralidade do cuidado físico e mental aos usuários do Sistema Único de Saúde (SUS).

Com inserção mais recente na área da saúde, em especial na atenção primária à saúde (APS), o PEF foi historicamente capacitado para atuar na educação, no esporte-competição (Souza e Loch, 2011), na recreação e no lazer e nas academias de fitness (Ghilardi, 1998). Assim, sua atuação no NASF acarreta uma série de desafios, entre os quais lidar com questões até então não usuais em sua prática cotidiana, tais como o trabalho em equipe constituída por outros profissionais da área da saúde e a realização de ações de promoção da saúde (PS) nos âmbitos individual e coletivo.

As políticas de promoção vêm acompanhando as mudanças sociais, econômicas, culturais e políticas que estão ocorrendo no cenário mundial e objetivam promover alterações positivas na sociedade, consequentemente na vida dos cidadãos (Brasil, 2007). Nesse sentido, a Política Nacional de Promoção da Saúde (PNPS) apresenta como objetivo geral "promover a qualidade de vida e reduzir vulnerabilidade e riscos à saúde relacionados aos seus determinantes e condicionantes - modos de viver, condições de trabalho, habitação, ambiente, educação, lazer, cultura, acesso a bens e serviços essenciais" (Brasil, 2006, p. 17). Pressupostos que, mesmo de forma não exclusiva, são incorporados pelo PEF no desenvolvimento de seu trabalho. Autores como Akerman, Mendes e Bógus (2004) preconizam que promover saúde significa potencializar recursos para uma vida plena dos cidadãos, pelo exercício de práticas sociais estruturadas na cooperação, solidariedade e transparência entre os sujeitos, questões essas também afeitas ao PEF.

Ao se inserir na APS - e consequentemente no NASF -, esse profissional passa então a conviver com uma nova realidade e, em consonância com o preconizado pela PNPS, a ter entre suas atribuições a realização de ações de promoção da saúde. Nesse contexto, acredita-se ser importante a investigação acerca do conhecimento e atuação desses profissionais no NASF no tocante a essas ações. Assim, o objetivo deste artigo foi analisar as ações de PS realizadas pelos PEFs nos NASFs em Minas Gerais. 


\section{Método}

O recorte apresentado neste artigo teve abordagem qualitativa e exploratória, utilizando a pesquisa documental e grupos focais (GFs) com informantes-chave como instrumentos de coleta de dados. Este trabalho integra o projeto de pesquisa "Programa de Promoção de Saúde e Prevenção da Violência na Atenção Básica".

Godoy (1995, p. 24) define a pesquisa documental como o "exame de materiais de natureza diversa, que ainda não receberam um tratamento analítico, ou que podem ser reexaminados, buscando-se novas e/ou interpretações complementares". A pesquisa documental objetivou analisar os documentos produzidos pelo Conselho Federal de Educação Física a partir de 1998, no que se refere à definição e regulação das atividades do PEF, com ênfase na APS. Foi realizada uma análise descritiva desses documentos, em que se procurou identificar os elementos relativos à inserção e atuação do PEF na APS, as quais serão objeto de outro artigo.

A técnica de grupo focal (GF) permite discutir em grupo, de forma interativa, um determinado assunto, acessando esses significados presentes no entrevistado por meio de seus atos, palavras, sentimentos e maneiras (Minayo, 2004; Flick, 2004).

Atendendo ao preconizado por Gatti (2005), realizaram-se dois GFs com a participação de sete e oito alunos cada. Os grupos contaram com a presença de um moderador e um observador e foram realizados no dia 15 de setembro de 2012, em duas salas, no oitavo andar da Faculdade de Medicina da Universidade Federal de Minas Gerais (UFMG), simultaneamente, com duração média de uma hora e trinta minutos.

Os informantes-chave participantes dos GFs foram PEFs matriculados no curso de especialização em atenção básica em saúde da família (CEABSF) da UFMG que estavam inseridos nos núcleos de apoio em saúde da família em Minas Gerais. O CEABSF é uma pós-graduação lato sensu, ofertada na modalidade educação a distância, que atende à demanda pública de formação em atenção básica dos profissionais inseridos nas equipes de saúde da família e nos NASFs.

Depois de gravadas em áudio, as falas foram transcritas. Os GFs tiveram como perguntas norteadoras: o que vocês entendem por promoção da saúde? No seu trabalho, no NASF, você desenvolve ações de PS? Quais fatores facilitam e quais fatores dificultam as ações de PS que vocês realizam no contexto do NASF?

Para a análise dos dados, utilizou-se a técnica de análise de conteúdo de Bardin (2008, p. 37), definida como o “conjunto de técnicas de análise das comunicações, que utiliza procedimentos sistemáticos e objetivos de descrição do conteúdo das mensagens". A análise dos dados levou à definição 
das seguintes categorias de análise: considerações sobre a PS, realização de ações de PS, facilidades e dificuldades para a realização de ações de PS.

Os participantes foram informados, no instante da coleta, do objetivo da pesquisa e dos procedimentos de coleta de dados que seriam utilizados. Todos os que acordaram em participar da pesquisa assinaram o termo de consentimento livre e esclarecido.

Este artigo é resultado da dissertação de mestrado intitulada "A promoção da saúde no Núcleo de Apoio à Saúde da Família: o papel do profissional de educação física", apresentada ao Programa de Pós-Graduação em Promoção da Saúde e Prevenção da Violência da Faculdade de Medicina da Universidade Federal de Minas Gerais (UFMG). A pesquisa foi aprovada pelo Comitê de Ética em Pesquisa da UFMG, mediante o certificado de apresentação para apreciação ética (CAAE) n. 01140812.1.0000.5149.

\section{Considerações sobre a promoção da saúde}

Os resultados apontam concepções de PS pelos entrevistados que vão desde um movimento com início antes da instalação da doença - que visa ao não adoecimento e à recuperação da saúde do indivíduo e da coletividade, e não se resume ao campo da atividade física $(\mathrm{AF})$ - até a realização de ações na busca por melhor qualidade de vida e adoção de hábitos saudáveis cotidianos, os quais contribuem para estimular os aspectos físico, mental, social e espiritual dos indivíduos. Os entrevistados entendem também a PS de forma multidimensional, o que remete à necessidade de se trabalhar o ser humano como um todo e não de forma fragmentada.

A própria palavra já diz - promoção é você colocar em foco mesmo a saúde, desfocar a doença (GF2).

A PS é justamente o trabalho antes que qualquer doença esteja instalada (GFl).

PS é orientar as pessoas, prevenir para não chegar a adoecer, divulgar os métodos de promover essa saúde, que é através da AF, bons hábitos alimentares, uma boa saúde psíquica, enfim, trabalhar o indivíduo como um todo (GF2).

Como o ser humano é multidimensional, a PS também tem que ser multidimensional; então não dá pra gente trabalhar apenas um aspecto isolado da saúde, a gente trabalha o ser humano como um todo. Não tem como dividir (GFl).

Tais concepções estão ancoradas em autores como Freitas e Mandú (2010, p. 201), para os quais, “ao se responsabilizar pela saúde da população territorializada, as equipes desse âmbito assistencial devem ampliar a prática 
curativo-preventiva do modelo biomédico tradicional, buscando promover, também, a qualidade de vida".

Já Marcondes (2004, p. 10) afirma que a PS está mais próxima “da qualidade de vida do que do controle das enfermidades". Para ele, essa é a diferença que orienta as ações de PS e prevenção de doenças.

Malta e colaboradores (2009) afirmam que a PS está relacionada com o modo de vida das comunidades e dos indivíduos, bem como com as transformações advindas dessas realidades. Ainda para esses autores, para pensar a PS é necessário se remeter a um número maior de ações e estratégias que visam valorizar e aumentar o potencial do indivíduo e da população em busca de um estilo de vida mais saudável.

\section{Realização de ações de promoção da saúde}

A análise dos dados demonstrou a realização de diferentes ações de PS, com destaque para o trabalho com grupos diversos - diabéticos, hipertensos, gestantes, tabagistas, adolescentes e idosos - desenvolvido por meio de diferentes estratégias, entre elas as práticas corporais, os exercícios e atividades físicas e as palestras. Constatou-se que as ações de PS são desenvolvidas tanto no âmbito individual quanto no coletivo. Os depoimentos também mencionaram a realização de grupos de nutrição, prevenção de quedas, cuidadores de idosos, saúde do adulto, combate à obesidade, saúde mental, hidroginástica, ginástica e caminhada, para diferentes faixas etárias.

Para a EF, o trabalho através de grupos operativos (...) é muito bem aceito, quase que é normal na nossa atuação trabalhar em grupo (GF2).

É importante que a gente trabalhe sim com a promoção tanto individual como em grupo (GF1).

Estamos formando grupos já fixos: nutrição, tabagismo, prevenção de quedas (GF1).

A gente trabalha com gestante, com idoso, com cuidador de idoso, com família de idoso (...) saúde do adulto, tabagismo (...) combate à obesidade (GF2).

Desenvolvo trabalho com hidroginástica, ginástica, caminhada com adultos, adolescentes, adultos e idosos (GF2).

Relataram que, muitas vezes, é nos grupos que o paciente tem a oportunidade de se informar e esclarecer dúvidas acerca de sua patologia, o que possibilita um novo olhar sobre ela. 
Muitas vezes o aluno (...) chega no grupo operativo, ali na conversa com a gente é que ele vai se informar melhor sobre o que é hipertensão, por que que ele toma aquele remédio, o que que o remédio vai fazer com o corpo dele, qual a diferença que vai ter. Ele passa a entender melhor um pouquinho do que que ele tá sofrendo (...) e aí cai naquele conceito de PS, ele passa a ter um conhecimento melhor (GF2).

O foco do grupo é na mudança de comportamento (...) valorizando o conhecimento que eles já têm, mas dando algumas informações (GF2).

Ao pesquisar um grupo de gestores de saúde, Andrello e colaboradores (2012) identificaram que, para eles, as ações de PS com enfoque na AF são importantes para grupos específicos, como diabéticos, hipertensos, gestantes e idosos, e apenas uma minoria se refere ao jovem.

Há também grupos com crianças com foco na qualidade de vida, os quais são desenvolvidos em conjunto com os pais e de forma interdisciplinar.

A gente desenvolve um grupo de qualidade de vida pro adulto e pra criança. No grupo de qualidade de vida para crianças a gente faz um trabalho com os pais e com os filhos. (...) é de conscientização mesmo, é interdisciplinar (...) A gente usa das brincadeiras (...) incluiu algumas falas (...) da importância deles 'tarem' fazendo aquilo do brincar (GF2).

Outra ação relatada foi a de orientação dos usuários. Os entrevistados reconheceram que apenas o repasse de informação não era suficiente para que os usuários adotassem hábitos mais saudáveis em seu cotidiano. Acreditavam que as mudanças ocorreriam à medida que o indivíduo se apropriasse de seus benefícios e os adotasse em seu dia a dia.

O papel é justamente possibilitar às pessoas a informação necessária para que elas consigam fazer escolhas saudáveis, autônomas e responsáveis (GF1).

PS é incentivar as pessoas a adotar hábitos de vidas mais saudáveis, (...) a gente não consegue mudar. Simplesmente passa para a pessoa as informações corretas (...) cabe a ela utilizar ou não, mas a gente tem que trabalhar para que a pessoa a cada dia vá apoderando das informações, não ficar focado no profissional (GF1).

Quantas vezes as pessoas estão muito mal informadas. (...) É nosso dever também como promotores da saúde (...) orientar essas pessoas nesse sentido (GF2).

Ferreira, Castiel e Cardoso (2011) e Bonfim, Costa e Monteiro (2012) ressaltam a importância de os profissionais fazerem o aconselhamento da população para demonstrar tanto os benefícios da adoção de hábitos saudáveis 
como a necessidade de eles estarem associados à prática de atividades físicas. Também a PNPS preconiza "o aconselhamento junto à população, sobre os benefícios de estilos de vida saudáveis" (Brasil, 2006, p. 34).

Bydlowski, Westphal e Pereira (2004) propõem estratégias para o empoderamento dos indivíduos, como o compartilhamento das informações, a realização de ações intersetoriais e multiprofissionais e a participação da população de maneira a opinar nas decisões e colaborar na elaboração de políticas.

Andrello e colaboradores (2012) afirmam que o usuário não deve ser apenas um receptor das informações a ele fornecidas, mas partícipe de um processo em que o diálogo permita a construção de um novo conhecimento, valorizando, assim, a informação como um processo de educação para a saúde na PS. Pinafo e colaboradores (2011) consideram que, além de levar a informação à população acerca dos problemas de saúde e da necessidade de se adotarem hábitos de vida saudáveis, é necessário cogitar os valores, costumes, modelos sociais, enxergar o usuário como sujeito.

A realização de avaliação física individual, atendimentos individuais, palestras, a organização de eventos, intervenções em escolas e a formação de parcerias institucionais também são relatadas como ações de PS.

As avaliações físicas (...) então é uma ação nossa de PS individual (GF2).

A gente trabalha com a PS nas intervenções através de palestras, grupos operativos, grupos de AF, grupos de caminhada, intervenções junto às escolas e formação de diversas parcerias intersetoriais (GF1).

De acordo com Malta e colaboradores (2009), para se atingir um cuidado integral em saúde é preciso estruturar um conjunto de estratégias capazes de alcançar individual e coletivamente os atores envolvidos. Souza e Loch (2011) verificaram que os PEFs inseridos nos NASFs trabalham tanto com grupos de atividades físicas como com minipalestras relacionadas à importância da AF.

Segundo os entrevistados, as palestras, com abordagem de temas diversos, são utilizadas por sua capacidade de informar, conscientizar, divulgar e aconselhar os usuários, de maneira a favorecer a adoção de hábitos saudáveis.

E a gente faz esse trabalho de promoção justamente no momento em que você realiza uma atividade - seja uma palestra com orientações de cuidados diversos, cuidados com o corpo, sobre hábitos de vida saudáveis - justamente para conscientizar aquelas pessoas (GF1).

A nossa equipe tem um trabalho (...) que inclui palestras (...) de prática diária de $\mathrm{AF}$, educação alimentar, também a parte psicológica (GF1). 
Os programas de AF voltados para o SUS, pesquisados por Bonfim, Costa e Monteiro (2012), demonstraram que alguns deles têm como objetivo conscientizar as pessoas sobre a importância da AF, associando ações educativas a procedimentos de intervenção.

As ações de combate ao sedentarismo são desenvolvidas por meio de práticas corporais, exercícios físicos, atividades físicas e caminhada orientada. Esta última é realizada em conjunto com a equipe de saúde da família. O trabalho em equipe foi valorizado pelos entrevistados como um importante aporte à execução de ações de PS.

Minha equipe NASF tá conseguindo desenvolver também junto com o PSF um grupo de caminhada orientada onde eu não preciso estar presente o tempo todo (...) eu monto o treinamento e eles vão ajudando nesse monitoramento (GF2).

Os estudos de Souza e Loch (2011) e Bonfim, Costa e Monteiro (2012) demonstraram que a caminhada e as aulas de ginástica são as ações mais utilizadas pelos PEFs, no NASF e em programas de atividades físicas.

Os entrevistados participavam também de outras iniciativas propostas em seus municípios, tais como os programas Academia Livre e Academia da Cidade, além de trabalho com deficientes visuais e crianças da Associação de Pais e Amigos dos Excepcionais (Apae).

Nosso programa se chama Academia Livre. A gente leva AF pra população adulta, pra população em geral. A gente tem um trabalho com cegos, deficientes visuais, com a terceira idade, com as crianças da Apae e também com o pessoal da saúde mental (GF2).

Por fim, a realização de encontro multidisciplinar, a qual agregou outros profissionais inseridos no NASF e também da sociedade em geral, foi mencionada como uma ação de PS.

Uma ação de PS (...) foi uma ação que nós denominamos como Encontro da Saúde, no qual o responsável foi o PEF em parceria com todos os outros profissionais, inclusive em parceria com a unidade básica de saúde e toda a equipe NASF. (...) apresentamos na questão da $\mathrm{AF}$, ginástica laboral, dança, lutas (...) parceria também da escola, (...) fizemos palestras sobre a questão da nutrição, da alimentação saudável, chamamos também a saúde bucal, onde falaram da importância da escovação (GF2).

Esses achados estão em consonância com as atividades que devem ser desenvolvidas pelos profissionais inseridos no NASF, elencadas por Malta e colaboradores (2009), tais como práticas corporais/atividades físicas (PCAFs); 
educação permanente em nutrição; ampliação e valorização do uso dos espaços públicos; ações multiprofissionais em reabilitação; atendimento a usuários e familiares em situação de risco e doença mental; e atenção aos agravos severos em crianças e mulheres.

\section{Fatores facilitadores para a realização de ações de promoção da saúde}

Uma facilidade apontada foi o maior incentivo que a prática de AF tem recebido dos três níveis de governo, com um aumento recente dos projetos na área.

Se nós retroagirmos até cinco anos atrás, a gente não teria tantos projetos destinados à pratica de AF. Hoje tem incentivo (...) da União (...) recém-implantada Academia da Saúde. (...) no nível estadual, vários projetos também que influenciam, por exemplo, Saúde na Praça (GF1).

Dentre as prioridades elencadas pelo MS na PNPS, está a organização das ações de PS que colocou em pauta as PCAFs. No contexto de mudanças epidemiológicas, em que se reconhece o sedentarismo como uma questão relevante, é importante pensar ações transversais, integradas e intersetoriais. Dessa forma, para viabilizar as práticas corporais, houve maior incentivo das três esferas de gestão do SUS para a prática de atividades físicas (Brasil, 2006; Malta et al., 2009).

De acordo com Bonfim, Costa e Monteiro (2012, p. 168), diante do aumento das doenças crônicas e da redução da prática de $\mathrm{AF}$,

o poder público passou a adotar iniciativas para incentivar e promover a prática regular de atividades físicas no Sistema Único de Saúde (SUS), visando à promoção da saúde e à qualidade de vida da população. Uma iniciativa importante foi a "Política Nacional de Promoção da Saúde - PNPS", implantada em 2006, bem como a criação do "Núcleo de Apoio à Saúde da Família - NASF", criado em 2008.

Outra facilidade é a reorientação do modelo de saúde, que, entre outras questões, propiciou a entrada do PEF na área, a participação da comunidade e a valorização do trabalho multiprofissional e intersetorial.

Essa mudança no modelo (...) é que tá permitindo essa facilidade, porque esse novo modelo de olhar para a comunidade, trazer a comunidade, participar, as atividades têm que ser de acordo com a localidade, com a região (GFl).

O modelo assistencial de saúde que o município adota. E o plano de saúde, de atenção básica de saúde, que esse município tá executando nas suas unidades. 
Vinculado a isso, a dinâmica da própria unidade, questão do trabalho intersetorial, multiprofissional, de cada profissional, estando ciente da sua missão, enquanto membro de uma equipe de saúde, do planejamento (GF1).

Questões que vão do espaço para desenvolvimento do trabalho ao estabelecimento de parcerias com a comunidade e liberdade profissional propiciando a criatividade são consideradas, pelos entrevistados, como facilidades à realização de ações de PS.

Espaço pra gente trabalhar, parcerias com as redes dentro das comunidades, a própria secretaria de Saúde (...) material (...) criatividade do profissional, a disponibilidade para poder realizar (...) poder fazer um pouco mais do que é seu dever e só. Eu acho que isso tudo são facilitadores para o nosso trabalho, para alcançar nosso objetivo, que é promover a saúde (GF2).

A utilização do planejamento e o consequente diagnóstico situacional dele decorrente foram apontados como facilitadores à realização de ações de PS. Este último permite caracterizar o território. Lembrou-se ainda do acolhimento, como prática capaz de permitir a identificação dos problemas e o planejamento das ações de acordo com o território.

Dos fatores que facilitam as ações, primeiro o planejamento (...) através do acolhimento a gente pode detectar os problemas e, através disso, a gente planeja as ações de acordo com cada local que a gente está atendendo (GFl).

A gente teve contato com diagnóstico situacional, acho que é um facilitador. Você passa a identificar com o que você pode lidar ali, o que você tem de estrutura (GF2).

Pinto, Menezes e Villa (2010) verificaram entre os profissionais da SF pesquisados que o conhecimento do território é um fator que facilita o processo de trabalho da equipe. Para Nascimento e Oliveira (2010), a formação do profissional que atua no NASF deve abordar o diagnóstico situacional, o planejamento em saúde e as intervenções.

A realização de eventos e sua capacidade de mobilizar a comunidade permitem maior divulgação do trabalho do NASF, o que facilita a realização das ações de PS.

Foi uma coisa que mobilizou até o jornal local, a Prefeitura. A gente começou a fazer grandes eventos que chamavam atenção, e eles começaram a investir (GF2).

Hoje a mídia facilita isso, a gente percebe programas na televisão falando sobre AF, falando sobre o benefício da PS (GFl). 
Mobiliza mesmo. É uma forma também de educar pra saúde, pra PS, esses eventos (GF2).

Cursar uma pós-graduação em atenção básica (CEABSF) também foi algo lembrado como uma facilidade ao desenvolvimento do trabalho no NASF.

E uma coisa que facilita demais também é a pós-graduação, a pós-graduação em SF que nós estamos realizando (GFl).

Pinto, Menezes e Villa (2010) identificaram como facilidade para desenvolver as atividades da Estratégia Saúde da Família (ESF) a presença de profissionais com conhecimento e perfil em saúde pública. Para Freitas e Mandú (2010), é preciso investir na educação permanente dos profissionais da SF, pois a PS requisita conhecimentos e habilidades integradas.

A abordagem do usuário pelo profissional, de forma dialogada, acessível e participativa, também é apresentada como facilidade.

Eu acho que a forma de abordagem, a forma de transmitir, isso é extremamente importante. (...) Então, a forma de começar a dialogar na linguagem bem coloquial (...) o carinho que você dá, de brincar com ele (...) isso facilita muito até mesmo o aprendizado do usuário e entendimento daquilo e torna mais fiel o grupo (GF1).

Nascimento e Oliveira (2010, p. 95) ressaltam o ato de acolher e de ouvir os usuários, bem como "flexibilidade, pró-atividade, resiliência, respeito, vínculo e comprometimento", como habilidades necessárias aos profissionais que atuam no NASF.

O reconhecimento pelos outros profissionais da equipe, o entendimento e o conhecimento acerca do papel do PEF, quando ocorrem, são indicados como facilitadores.

"Você tem que fazer uma caminhada." Não, você não tem que fazer uma caminhada, você tem que ser avaliado por um PEF. Quem vai prescrever exercício para você é ele, ele é a pessoa que está mais apta. Então, quando os outros profissionais têm esse entendimento, isso facilita muito o nosso trabalho (GF1).

Um fator que com certeza facilita o trabalho é o respeito que os outros profissionais do próprio NASF e também da unidade têm com o PEF, justamente pelo retorno das suas atividades (GF1).

A facilidade que eu encontro hoje é você ser um profissional dentro do centro de saúde (...) você é visto como um profissional da saúde (GF2). 
Também o entrosamento da equipe e o apoio de seus integrantes, em especial do médico, foram apontados como facilitadores do trabalho do PEF.

Um fator importante nessa construção é o entrosamento da equipe. Se a equipe não estiver entrosada, não pensar da mesma forma, cada um vai trabalhar de forma separada (GF2).

Os médicos apoiam as atividades, mesmo se isso tá atrapalhando os atendimentos deles. Então isso motiva a gente, isso é fator facilitador, motiva a gente a continuar (GF2).

Pinto, Menezes e Villa (2010), ao pesquisarem profissionais da ESF, identificaram o entrosamento entre seus integrantes como um fator que facilita o desempenho do trabalho. O estudo de Souza e Loch (2011) constatou que os PEFs consideram o trabalho interdisciplinar como grande oportunidade para a troca de conhecimento, o que favorece o trabalho coletivo.

\section{Fatores dificultadores para a realização de ações de promoção da saúde}

Foram elencados diversos fatores que dificultam a realização de ações de PS, entre eles a falta de infraestrutura, tanto física como de materiais e equipamentos necessários ao desenvolvimento do trabalho.

Um dos fatores é a estrutura física mesmo. Às vezes, a gente não tem espaço dentro do posto, às vezes não tem uma igreja do lado ou então uma praça que possa contribuir para fazer essas atividades nos grupos. (...) a gente trabalha com material alternativo, mas acredito que a falta de material, de um som, de um equipamento bacana, que chama a atenção, também prejudica (GF1).

A falta de materiais e instrumentos, segundo Pinto, Menezes e Villa (2010), é um fator que não colabora para a execução das atividades no dia a dia. De acordo com Souza e Loch (2011), a falta de espaços adequados para a realização das atividades também é uma dificuldade para o PEF.

Outra dificuldade se referiu ao funcionamento da unidade de saúde, uma vez que os horários nos quais se desenvolviam as atividades muitas vezes não eram compatíveis com as possibilidades dos usuários. Foram citadas também duas questões relativas a acesso, que dificultavam as ações do PEF. A primeira dizia respeito à presença de violência na região, o que afastava os usuários. A segunda se referia à localização da unidade, o que dificultava o acesso de determinados públicos, em especial aqueles que, morando na área rural, dependiam de transporte. 
A localização do posto também eu acho que pode vir a afastar um pouco o público, por ser violento, difícil acesso (GF1).

Uma das maiores dificuldades é isso, é o acesso até o local que vai fazer as atividades (GF1).

E o público adulto tem uma dificuldade muito grande, porque o horário de trabalho dos funcionários do NASF e o horário de funcionamento da própria unidade de saúde coincidem com o horário de trabalho dessas pessoas (GF1).

No que tange aos grupos, apontou-se maior participação de mulheres e idosos em contraposição à menor participação de crianças, adolescentes e homens. Para os entrevistados, os adultos e jovens consideravam os grupos de trabalho desnecessários, por se sentirem em boa saúde. Assim, acreditavam ser importante atuar nas escolas, de forma a atender as crianças e adolescentes.

A gente tem dificuldade para tá atingindo a população adulta e a população de adolescentes e crianças. Com os adolescentes e crianças, a estratégia que a gente tá utilizando é não levá-los até a unidade de saúde; é a gente ir nos locais onde eles estão justamente, fazer um trabalho com parcerias das escolas. A gente faz o trabalho de prevenção e PS do adolescente já dentro da escola (GF1).

Por que só os mais idosos, por que só o público feminino? Aí vai na questão da mentalidade. Os idosos é porque eles tão precisando mesmo, tão sentindo alguma dor, teve alguma indicação (GF1).

Tais achados estão em consonância com o estudo de Souza e Loch (2011), o qual verificou que os grupos que mais participam das atividades físicas são idosos e mulheres que apresentam patologias. Os autores constataram ainda baixa participação da comunidade nos grupos de atendimento, quando comparada com o número de pessoas do território. Hallal e colaboradores (2010) também identificaram as mulheres como a categoria de maior participação nos programas de atividades físicas na cidade de Recife (PE).

O reduzido número de PEFs atuando no NASF, a ausência de transporte para o deslocamento de um polo para o outro, a cobrança por produtividade, a impossibilidade de acompanhamento do tratamento do paciente e, por fim, a solidão advinda da ausência de outro PEF para compartilhamento do trabalho foram outros itens destacados.

Lá no meu município nós somos dois profissionais de saúde no NASF. A gente trabalha integral (...) mas a quantidade de profissionais, ela não é suficiente, porque 
são 13 unidades de saúde para apenas esses dois profissionais conseguirem desenvolver todo esse trabalho (GF1).

A gente do interior reclama (...) a gente fica sozinha, fica muito sozinha (GF2).

Em alguns locais, a carga horária semanal prescrita para o PEF e sua lotação em mais de um serviço, ou seja, sua atuação em diversos polos, com pouco tempo disponível em cada um deles, o que leva a um comprometimento do trabalho, também foram indicadas como dificuldades. Para tais entrevistados, o trabalho seria mais bem desenvolvido se o PEF, à semelhança de outros profissionais, atuasse de forma exclusiva no NASF.

O que tem dificultado o trabalho é a questão da carga horária (...). O educador físico (...) trabalha com trinta horas na Academia da Cidade e dez horas no NASF. Então essas dez horas no NASF são insuficientes para ele desenvolver um trabalho, e às vezes ele fica 'desentoado' dos outros profissionais, que são específicos do NASF (...) o ideal seria um PEF (...) exclusivo pro NASF (GF1).

A dificuldade de mudança do paradigma de atendimento curativo para o da PS, mesmo após a criação do Programa Saúde da Família (PSF), bem como a concepção dos outros profissionais sobre as ações de PS, também foi destacada. Avaliou-se que estes ainda estavam muito voltados para as ações clínicas e trabalhavam de forma isolada, em detrimento de ações de PS desenvolvidas coletivamente. A maior valorização pela população sobre o atendimento individual em detrimento dos grupos fazia com que tanto os profissionais da saúde quanto as comunidades atendidas ainda não vissem as unidades de saúde como um local de PS.

Justamente a questão sobre a mudança do paradigma de saúde (...) aquela cultura médico-centrista, voltada para a atenção à doença, ao aspecto curativo, ainda está muito enraizada, não só nos profissionais de saúde, mas também na população (GF1).

A população não vê o centro de saúde, a unidade básica de saúde, como um local mesmo de PS (GF1).

Mas se você for avaliar o trabalho de cada um [dos profissionais do NASF], eles ainda estão muito voltados a ações clínicas (GF2).

É difícil, tá sendo difícil mudar a ideia de que a prevenção e a promoção trazem mais resultado através dos grupos operativos do que com atendimentos individuais. Pra população é difícil entender que ela vai participar de um grupo com problemas psicológicos, porque ela quer ser atendida individualmente; e até para 
os próprios profissionais da área da saúde, quando a gente fala que o nosso atendimento é através de grupos operativos, ele não é tão aceito como deveria ser (GF2).

Souza e Loch (2011) enfatizam que as ações de PS não devem ter um direcionamento apenas clínico, para que possam abranger a maior parte da população do território.

O não entendimento e o desconhecimento do papel do PEF - bem como de suas potencialidades - no NASF pelos demais profissionais foram mencionados como dificuldades.

O principal dificultador (...) é a falta de conhecimento em relação ao profissional (...) não saberem como que pode utilizar o profissional, a melhor forma do profissional dentro do espaço de trabalho (GF2).

Você chega, o pior é o desconhecimento. Você cai no posto, a pessoa que tá no posto (...) ele não sabe para que o profissional está ali. (...) como que ele pode ser útil. Acho que o principal erro no NASF hoje em dia é esse. Ele solta o profissional. Você se vira pra arrumar seu espaço, entendeu? (GF2).

Cobram da gente coisas que não são pertinentes a nossa área, (...) a gente não tem um referencial técnico, a gente não tem ninguém pra gente responder (GF2).

Comecei realmente sem apoio nenhum, sem um norte (...) fica dependendo muito da gente, se tenho criatividade, eu vou lutar, mostrar alguma ação. Se eu não tenho, alguns profissionais vão ficar assim e aí vão continuar assim (GF2).

No que se refere a essas questões, em que pese o fato de o Caderno de Atenção Básica (CAB 27), publicado pelo Ministério da Saúde (Brasil, 2010), definir para os diversos profissionais atuantes no NASF as atividades comuns, percebe-se ainda haver dificuldades de entendimento relacionadas ao PEF. O NASF é composto por nove áreas estratégicas temáticas, cujas diretrizes e principais ações a serem desenvolvidas são elencadas no CAB 27. Contudo, como o próprio texto do caderno aponta, "tais áreas estratégicas não se remetem a atuação específica e exclusiva de uma categoria profissional" (Brasil, 2010, p. 31). Destaca ainda que "o que deverá definir se a ação é do nutricionista ou de outro profissional é a situação, ou seja, a necessidade da população e as características da equipe. E assim sucessivamente para todas as áreas estratégicas" (Brasil, 2010, p. 31).

No que tange ao PEF, considera-se que a área 'práticas corporais/atividades físicas' dialoga mais proximamente com seu campo de atuação. Ao definir as responsabilidades profissionais nas PCAFs, o CAB 27 recomenda que o PEF 
favoreça em seu trabalho a abordagem da diversidade das manifestações da cultura corporal presentes localmente e as que são difundidas nacionalmente, procurando fugir do aprisionamento técnico pedagógico dos conteúdos clássicos da educação física, seja no campo do esporte, das ginásticas e danças, bem como na ênfase à prática de exercícios físicos atrelados à avaliação antropométrica e à performance humana (Brasil, 2010, p. 31).

Falci (2013) verificou que muitos PEFs que atuam no NASF desenvolveram sua própria forma de trabalho em razão da inexistência de uma definição das atribuições do PEF e do seu trabalho na APS. Da mesma forma, Andrello e colaboradores (2012) acreditam que a atuação do PEF na APS precisa ser mais bem definida. Para Santos e Benedetti (2012, p. 193), “a Educação Física, apesar de estar vinculada à prevenção e PS, possui pouca experiência prática nos serviços públicos, logo enfrenta um desafio para definição do seu papel profissional e competências necessárias para atuação junto ao SUS".

Outro ponto abordado pelo $\mathrm{CAB} 27$ se refere ao denominado apoio matricial entendido como uma tecnologia de gestão que se complementa com o processo de trabalho em equipes de referência (Brasil, 2010). O CAB 27 preconiza que "o apoio matricial será formado por um conjunto de profissionais que não têm, necessariamente, relação direta e cotidiana com o usuário, mas cujas tarefas serão de prestar apoio às equipes de referência (equipes de SF)" (Brasil, 2010, p. 11), apontando as dimensões de suporte, assistencial e técnico-pedagógica desse apoio.

Observa-se que, a despeito de sua importância, a discussão acerca do apoio matricial não surgiu nos depoimentos dos entrevistados. Uma vez que o apoio matricial se baseia no compartilhamento de saberes entre os profissionais de maneira a colaborar com a resolutividade das demandas identificadas (Brasil, 2010) - e os relatos indicam uma prática ainda individual do PEF com tímidas iniciativas de trabalho em equipe -, infere-se que as questões apontadas em relação à equipe de trabalho - tais como falta de comunicação e de apoio dos demais profissionais e pouca coordenação entre as ações dos PEFs e dos demais profissionais do NASF e entre os próprios NASFs - podem atuar como dificultadores desse processo.

Tem [equipe de] SF que a gente não tem apoio adequado pra fazer AF em grupo, a gente faz no meio da unidade, debaixo da janela dos médicos e das enfermeiras (GF2).

A gente observa que não tem uma grande coordenação de ações dos PEF do NASF e dos profissionais das outras profissões que atuam no NASF (GF2).

A gente não tem integração nenhuma com o pessoal fora do nosso município nos NASF (...) não tem apoio, a gente não tem integração entre outro NASF (GF2). 
A portaria GM/MS n. 2.488, de 21 de outubro de 2011, recomenda que haja entrosamento entre os municípios-sedes de NASF, o que contribuiria para criar um espaço de compartilhamento de experiências, no intuito de colaborar com as intervenções dos profissionais.

Com relação à capacitação dos profissionais, os PEFs afirmam que há pouco incentivo por parte do município, enquanto que as capacitações oferecidas a outros profissionais não os contemplam, o que faz com que as soluções sejam procuradas individualmente.

O educador físico, ele tá no grupo (...). Aí, quando sai uma qualificação, só vai o médico e o enfermeiro (GF2).

Outro fator observado é falta de capacitação. Nunca existiu capacitação no NASF, nas outras equipes. Sempre a gente que corre atrás (GF1).

De acordo com Bonfim, Costa e Monteiro (2012), o ingresso dos PEFs no NASF evidenciou o pouco preparo desses profissionais para atuar na saúde coletiva, demonstrando a necessidade de capacitá-los para trabalhar na atenção primária.

Os depoentes consideraram sua formação insuficiente para o desempenho das funções no NASF, relatando falta de conhecimento clínico e dificuldade para lidar com áreas específicas. Comentaram a ausência de disciplinas relativas à saúde pública no curso de graduação e a necessidade de buscar mais conhecimentos.

Por melhor que seja sua formação (...) acho que às vezes falta (...) conhecimento clínico (...) eu não tenho preparo nenhum pra trabalhar com saúde mental, que eu nunca tive nenhuma disciplina voltada pra saúde mental (GF2).

Na graduação, a gente não tem disciplina de saúde pública. É uma coisa que hoje, se a gente tá querendo entrar, o negócio tem que estar lá, pra você já graduar com isso (GF2).

Resultados semelhantes foram encontrados por Falci (2013), que identificou entre os PEFs pesquisados o reconhecimento da insuficiência de sua formação para a atuação na APS. Souza e Loch (2011) destacaram que o curso de graduação em EF não tem proximidade com a área de saúde pública, levando à necessidade da busca de novos conhecimentos. Santos e Benedetti (2012) acreditam que tal situação se deve ao enfoque curativo e prescritivo abordado nos cursos de graduação em EF. 


\section{Considerações finais}

Os resultados indicaram que os entrevistados não só tinham um entendimento amplo do conceito de PS como desenvolviam ações no sentido de alcançá-la.

Observou-se que as ações de promoção da saúde realizadas pelo PEF no NASF eram abrangentes, diversificadas e desenvolvidas em conjunto com a equipe e a comunidade. Atendiam a diferentes faixas etárias, grupos específicos e vulneráveis e eram desenvolvidas por meio de diversas abordagens, tais como trabalho com grupos, orientação aos usuários, realização de avaliação física individual, atendimentos individuais, diferentes tipos de exercícios e atividades físicas, palestras, intervenções em escolas, formação de parcerias institucionais, realização de eventos e participação em diferentes iniciativas institucionais.

Foram expostos fatores dificultadores e facilitadores à realização dessas ações. Entre as facilidades para a realização de ações de PS, foram elencadas a reorientação do modelo de saúde, a participação da comunidade, a valorização do trabalho multiprofissional e intersetorial e o incentivo governamental para as práticas de atividades físicas.

Entre as dificuldades, destacaram-se a falta de infraestrutura, a falta de orientação e direcionamento quanto ao trabalho a ser realizado, a não compreensão do papel do PEF por parte dos demais profissionais, a falta de capacitação, o não entendimento pelos demais profissionais da mudança do paradigma de atendimento curativo para o da PS e a concepção destes ainda voltada para as ações clínicas individuais, em detrimento de ações de PS coletivas. Assim, o desenvolvimento de ações de PS pelos PEFs ainda se apresentou como um grande e positivo desafio.

Os entrevistados apontaram a necessidade de consolidar seu papel na equipe, demonstrar competência e ganhar confiança e fidelidade da comunidade, por meio de trabalho contínuo e bem realizado.

Tal realidade evidenciou a necessidade de maior mobilização da categoria no sentido de estabelecer canais de comunicação com os demais profissionais e com os gestores.

Finaliza-se reconhecendo que as limitações desse estudo torna necessária a realização de outras pesquisas e abordagens sobre o tema. Contudo, espera-se que as questões aqui apresentadas possam contribuir para uma melhor compreensão do PEF enquanto um profissional inserido na APS, bem como para a discussão acerca do seu papel no desenvolvimento de ações de PS. 


\section{Colaboradores}

Gisele Marcolino Saporetti foi responsável pela concepção, delineamento do estudo, análise e interpretação dos dados, redação do artigo e aprovação da versão final. Paulo Sérgio Carneiro Miranda participou da concepção e delineamento do estudo, revisão crítica e aprovação da versão final. Soraya Almeida Belisário participou da concepção e delineamento do estudo, análise e interpretação dos dados, revisão crítica e aprovação da versão final. Não há conflito de interesses.

Resumen Los núcleos de apoyo a la salud de la familia se configuran hoy como un locus de inserción del profesional de educación física en la atención primaria a la salud. Este hecho trajo nuevos desafíos a la actuación de este profesional, como la realización de acciones de promoción de salud en ámbitos individuales y colectivos. El objetivo del artículo es analizar las acciones realizadas por dicho profesional, en esos núcleos, en el estado de Minas Gerais, Brasil, en 2015. Se trata de una investigación cualitativa y exploratoria, que utilizó la búsqueda documental y grupos focales con 15 participantes como instrumentos de recolección de datos. Los resultados demostraron concepciones distintas y complementarias acerca del concepto de promoción de la salud y la realización de acciones de promoción abarcativas, diversificadas y en conjunto con el equipo y la comunidad. La reorientación del modelo de salud, la participación de la comunidad, la valoración del trabajo multiprofesional e intersectorial y el incentivo gubernamental para la práctica de actividades físicas fueron señalados como elementos que facilitan la realización de estas acciones. Entre las dificultades, se destacaron la falta de infraestructura y de capacitación, así como la concepción de los demás profesionales, aún dirigidas hacia acciones clínicas individuales, en detrimento de acciones colectivas de promociones de salud.

Palabras clave personal de la salud; educación física; atención primaria a la salud; promoción de la salud.

\section{Notas}

1 Universidade Federal de Minas Gerais, Núcleo de Educação em Saúde Coletiva, Belo Horizonte, Minas Gerais, Brasil.

<giselesaporetti@yahoo.com.br>

Correspondência: Av. Professor Alfredo Balena, 190, sala 708, Santa Efigênia, CEP 30130-100, Belo Horizonte, Minas Gerais, Brasil.

2 Universidade Federal de Minas Gerais, Faculdade de Medicina, Departamento de Medicina Preventiva e Social, Belo Horizonte, Minas Gerais, Brasil.

<pmiranda@medicina.ufmg.br> 
3 Universidade Federal de Minas Gerais, Faculdade de Medicina, Departamento de Medicina Preventiva e Social, Belo Horizonte, Minas Gerais, Brasil.

<soraya@nescon.medicina.ufmg.br>

\section{Referências}

AKERMAN, Marco; MENDES, Rosilda; BÓGUS, Cláudia M. É possível avaliar um imperativo ético? Ciência \& Saúde Coletiva, Rio de Janeiro, v. 9, n. 3, p. 605-615, 2004. Disponível em: <www.scielo.br/pdf/csc/v9n3/ a08v09n3.pdf> . Acesso em: 23 mar. 2013.

ANDRELLO, Eduardo et al. Atividade física e saúde pública sob o olhar de secretários municipais de Saúde. Revista Brasileira de Atividade Física \& Saúde, Pelotas, v. 17, n. 3, p. 206-211, 2012.

BARDIN, Laurence. Análise de conteúdo. 4. ed. Lisboa: Edições 70, 2008.

BONFIM, Mariana R.; COSTA, José L. R.; MONTEIRO, Henrique L. Ações de educação física na saúde coletiva brasileira: expectativas versus evidências. Revista Brasileira de Atividade Física \& Saúde, Pelotas, v. 17, n. 3, p. 167-173, 2012.

BRASIL. Ministério da Saúde. Secretaria de Vigilância em Saúde. Política Nacional de Promoção da Saúde. Brasília: Ministério da Saúde, 2006.

BRASIL. Conselho Nacional de Secretários de Saúde. Atenção primária e promoção da saúde. Brasília: CONASS, 2007.

BRASIL. Ministério da Saúde. Portaria GM/MS n. 154, de 24 de janeiro de 2008. Cria os núcleos de saúde da família - NASF. Brasília: Ministério da Saúde, 2008. Disponível em: $<$ http://189.28.128.100/dab/docs/legislacao/ portarial54_04_03_08_re.pdf > . Acesso em: 23 mar. 2013.
BRASIL. Ministério da Saúde. Diretrizes do NASF: Núcleo de Apoio à Saúde da Família. Caderno de Atenção Básica, n. 27. Brasília: Ministério da Saúde, 2010. Disponível em: $<$ http://bvsms.saude.gov.br/bvs/publicacoes/ diretrizes_do_nasf_nucleo.pdf $>$. Acesso em: 23 mar. 2013.

BYDLOWSKI, Cynthia R.; WESTPHAL, Marcia F.; PEREIRA, Isabel Maria T. B. Promoção da saúde: porque sim e porque ainda não! Saúde e Sociedade, São Paulo, v. 13, n. 1, p. 14-24, 2004.

FALCI, Denise M. Formação para atenção primária à saúde: um estudo de caso da turma de profissionais de educação física do curso de especialização em atenção básica em saúde da família da UFMG. 77f. Dissertação (Mestrado em Saúde Pública) - Faculdade de Medicina, Universidade Federal de Minas Gerais, Belo Horizonte, 2013.

FERREIRA, Marcos S.; CASTIEL, Luís D.; CARDOSO, Maria H. C. A. Atividade física na perspectiva da nova promoção da saúde: contradições de um programa institucional. Ciência \& Saúde Coletiva, Rio de Janeiro, v. 16, supl. 1, p. 865-872, 2011.

FLICK, Uwe. Uma introdução à pesquisa qualitativa. 2. ed. Porto Alegre: Bookman, 2004.

FREITAS, Maria L. A.; MANDÚ, Edir N. T. Promoção da saúde na Estratégia Saúde da Família: análise de políticas brasileiras. Acta Paulista de Enfermagem, São Paulo, v. 23, n. 2, p. 200-205, 2010. 
GATTI, Bernadete A. Grupo focal nas ciências sociais e humanas. Brasília: Líber Livro, 2005. (Série Pesquisa em Educação, v. 10).

GHILARDI, Reginaldo. Formação profissional em educação física: a relação teoria e prática. Motriz, Rio Claro, SP, v. 4, n. 1, p. 1-11, 1998.

GODOY, Arilda S. Pesquisa qualitativa: tipos fundamentais. Revista de Administração de Empresas, São Paulo, v. 35, n. 3, p. 20-29, 1995.

HALLAL, Pedro C. et al. Avaliação do programa de promoção da atividade física Academia da Cidade de Recife, Pernambuco, Brasil: percepções de usuários e não usuários. Cadernos de Saúde Pública, Rio de Janeiro, v. 26, n. 1, p. 70-78, 2010.

MALTA, Débora C. et al. A Política Nacional de Promoção da Saúde e a agenda da atividade física no contexto do SUS. Epidemiologia e Serviços de Saúde, Brasília, v. 18, n. 1, p. 79-86, jan.-mar. 2009.

MARCONDES, Willer B. A convergência de referências na promoção da saúde. Saúde e Sociedade, São Paulo, v. 13, n. 1, p. 5-13, 2004.

MINAYO, Maria C. S. O desafio do conhecimento: pesquisa qualitativa em saúde. 8. ed. São Paulo: Hucitec, 2004.
NASCIMENTO, Débora D. G.; OLIVEIRA, Maria A. C. Reflexões sobre as competências profissionais para o processo de trabalho nos núcleos de apoio à saúde da família. O Mundo da Saúde, São Paulo, v. 4, n. 1, p. 92-96, 2010.

PINAFO, Elisangela et al. Relações entre concepções e práticas de educação em saúde na visão de uma equipe de saúde da família. Trabalho, Educação e Saúde, Rio de Janeiro, v. 9, n. 2, p. 201-221, 2011.

PINTO, Erika S. G.; MENEZES, Rejane M. P.; VILLA, Tereza C. S. Situação de trabalho dos profissionais da Estratégia Saúde da Família em Ceará-Mirim. Revista da Escola de Enfermagem da USP, São Paulo, v. 44, n. 3, p. 657-664, 2010.

SANTOS, Sueyla F. S.; BENEDETTI, Tânia R. B. Inserção da educação física no Núcleo de Apoio à Saúde da Família. Revista Brasileira de Atividade Física \& Saúde, Pelotas, v. 17, n. 3, p. 188-194, 2012.

SOUZA, Silvana C.; LOCH, Mathias R. Intervenção do profissional de educação física nos núcleos de apoio à saúde da família em municípios do norte do Paraná. Revista Brasileira de Atividade Física \& Saúde, Pelotas, v. 16, n. 1, p. 5-10, 2011.

Recebido em 17/09/2013

Aprovado em 01/08/2014 